\title{
Anchoring a halogenated amine on the surface of a microporous activated carbon for carbon dioxide capture
}

\author{
Amirhossein Houshmand, Mohammad Saleh Shafeeyan, Arash Arami-Niya, Wan Mohd Ashri Wan Daud * \\ Department of Chemical Engineering, Faculty of Engineering, University of Malaya, 50603 Kuala Lumpur, Malaysia
}

\section{A R T I C L E I N F O}

\section{Article history:}

Received 13 July 2012

Received in revised form 9 January 2013

Accepted 13 January 2013

Available online 16 March 2013

\section{Keywords:}

Activated carbon

Surface modification

Anchoring

Amino groups

Halogenated amine

\begin{abstract}
A B S T R A C T
Activated carbon (AC) surface may be modified by grafting amine-containing compounds to improve the $\mathrm{CO}_{2}$ adsorption capacity. Two solid sorbents were prepared by anchoring a halogenated amine, i.e., 2chloroethylamine hydrochloric acid (CEA) on the surface of a microporous AC using a two-stage modification. At the first stage, the samples of AC were oxidized by nitric acid to increase the amount of oxygen surface groups and at the second stage, the oxidized samples were modified by anchoring CEA on the surface to produce a superior $\mathrm{CO}_{2}$ adsorbent. The oxidized samples were compared with the aid of proximate and ultimate analysis, nitrogen adsorption-desorption at $-196{ }^{\circ} \mathrm{C}(77 \mathrm{~K})$ and temperature programmed desorption (TPD) to decide on the best oxidation conditions. The amine-modified samples were analyzed in terms of texture, surface chemistry and $\mathrm{CO}_{2}$ adsorption. The latter was studied using isothermal $\mathrm{CO}_{2}$ capture, temperature-programmed (TP) $\mathrm{CO}_{2}$ adsorption and cyclic operation. The modified samples had a lower surface area than the parent sample. The best modified sample presented an increase of $45 \%$ in $\mathrm{CO}_{2}$ capture capacity at $100{ }^{\circ} \mathrm{C}$. Based on unit surface area, the modified samples showed great $\mathrm{CO}_{2}$ capture capacities, compared to the virgin sample. Moreover, the modified samples presented a less dependency of $\mathrm{CO}_{2}$ capacity on temperature. This indicates that the adsorption mechanism shifts from physisorption to chemisorption by increasing temperature.
\end{abstract}

(c) 2013 Taiwan Institute of Chemical Engineers. Published by Elsevier B.V. All rights reserved.

\section{Introduction}

Climate change and global warming as a concern of this century is led by emission of greenhouse gases such as carbon dioxide, methane, chlorofluorocarbons (CFCs), ozone and nitrous oxide into the atmosphere [1,2].

Greenhouse effects of chlorofluorocarbons and methane are much higher than carbon dioxide when they are compared in mass unit [2]. However, $\mathrm{CO}_{2}$ is by far the most important contributor to the global warming due to its high emitted amount by using fossil fuels, which supply around $98 \%$ of energy requirement worldwide [3]. According to IPCC, global average of anthropogenic $\mathrm{CO}_{2}$ emission in the last decade of twentieth century was around $27 \times 10^{9}$ metric tons per year [4].

Growth in demand for energy in 21st century with the consideration of the point that fossil fuel is still the major source of energy caused a great attraction toward developing solutions to mitigate anthropogenic $\mathrm{CO}_{2}$ emission.

\footnotetext{
* Corresponding author. Tel.: +60 3 79675297; fax: +60 379675319.

E-mail addresses: amir.hshmnd@gmail.com (A. Houshmand), ms.shafeeyan@gmail.com (M.S. Shafeeyan), arash.araminiya@gmail.com (A. Arami-Niya), ashri@um.edu.my (W.M.A.W. Daud).
}

Three general strategies can be thought to cut down the released amount of $\mathrm{CO}_{2}$ [2]. The first one is increasing energy efficiency, which decreases "energy intensity". The second is using energy sources other than fossil fuels to decrease "carbon intensity" and the last one is capture and sequestration of $\mathrm{CO}_{2}$ (CCS).

CCS can be considered as a short- or mid-term, but not longterm, solution to the global warming problem, while new sources of energy such as nuclear, solar and biomass, are matured and developed enough to replace fossil fuels safely and economically [5,6]. Different approaches are currently being developed for both stages of CCS. For sequestration of $\mathrm{CO}_{2}$, a variety of geoengineering technologies including storage in terrestrial ecosystems, geological formation (e.g. emptied fields of oil and gas and deep saline formations) and deep ocean are possible $[7,8] . \mathrm{CO}_{2}$ capture is the first and most consuming stage of CCS [2]. It takes approximately $70-80 \%$ of CCS total cost [8].

Several methods including absorption (amine scrubbing), adsorption, cryogenic distillation and membrane separation are under use and progressive development for $\mathrm{CO}_{2}$ capture $[6,9,10]$. Of these ways, absorption by different amine solutions has been higher developed compared with other methods and so is the most conventional one. However, it has several drawbacks such as being energy sensitive (due to high energy requirement for regeneration step), corrosion, solvent degradation (causing restricted lifetime), 
solvent loss (due to amine volatility), side-reaction of solvent with NO $x$ and SO $x$ (that produces stable by-products) and limited amine concentration in the aqueous phase due to viscosity and foaming effect $[8,11-18]$.

$\mathrm{CO}_{2}$ capture is not limited to postcombustion (flue gas) application, which is resulted from global warming concerns. Other applications are in natural gas processing, syngas purification for hydrogen production (where PSA has already been established), fuel cell industries and $\mathrm{CO}_{2}$ removal from closed spaces of submarines and space shuttles $[11,17,18]$.

Due to versatile advantages of adsorption, usage of solid sorbents has been appeared as one of the promising options for $\mathrm{CO}_{2}$ capture. Adsorption requires lower energy, compared to absorption by amine solutions [6]. Development of adsorbents for $\mathrm{CO}_{2}$ capture is greatly paid attention in these years by modifying them using a variety of methods. In order to decrease the cost of $\mathrm{CO}_{2}$ capture by adsorption (for instance in a pressure swing adsorption process) and make the process of adsorption successful and competitive, it is necessary to develop adsorbents with high capture capacity (particularly in moderate temperature for flue gas application), high desorption rate and high selectivity $[3,18]$.

Adsorption capacity of an adsorbate like $\mathrm{CO}_{2}$ is determined by surface area, pore size, adsorbent surface chemistry, temperature and partial pressure/concentration of the adsorbate [6,7]. Adsorbent surface area presents nonspecific interaction between adsorbent and adsorbate, and surface chemistry determines specific interaction. In the absence of specific interaction (i.e. in physical adsorption), pore size and volume are important, so microporous adsorbents are suitable for capture of low-molecular weight gases [19]. In the case of physical adsorption, pore size of the adsorbent determines the adsorption potential energy and so affects some of adsorption characteristics such as regeneration energy requirements and regeneration temperature. As a comparison of the roles of texture and surface chemistry of the activated carbon in the adsorption capacity, we can say that the former governs the capacity, but the latter influences it strongly [5]. Thermodynamic of adsorption, i.e. equilibrium isotherm is the first item that has to be considered for adsorbent selection and kinetic of adsorption is the second important factor [20].

There are a variety of porous materials such as zeolite, polymers, silica and activated carbon (AC) that can be regarded as $\mathrm{CO}_{2}$ adsorbents. Compared with the other adsorbents, $\mathrm{AC}$ is cheap, stable against heat, radiation and alkaline and acidic solution $[21,22]$. It does not show too much shrinkage or swelling by $\mathrm{pH}$ change.

$\mathrm{AC}$ is a suitable adsorbent for $\mathrm{CO}_{2}$ capture from a wet gas streams, whereas other adsorbents such as zeolite need a dehumidification (pre-drying) process of gas stream as a preliminary step, due to water adsorption on zeolite that inhibit $\mathrm{CO}_{2}$ adsorption $[6,17,20]$. Dehumidification process consumes about $30 \%$ of total energy $[9,23]$ in a common PSA or TSA (temperature swing adsorption) process. Zeolites usually are low-efficient and high-cost in regeneration because of their small pore systems $[24,25]$ with a regeneration temperature $300{ }^{\circ} \mathrm{C}$ and above $[17,20]$, whereas $A C$ regeneration is carried out at lower temperatures. AC has a lower adsorption heat compared to zeolite [6].

One important problem associated with common solid adsorbents it that $\mathrm{CO}_{2}$ adsorption capacity of these adsorbents drops dramatically with increasing temperature [7]. Temperature increase molecular diffusivity and surface adsorption energy [7]. Flue gas, as a main application of $\mathrm{CO}_{2}$ capture, has a temperature between 50 and $120^{\circ} \mathrm{C}$. For $\mathrm{CO}_{2}$ adsorption from flue gas, either the flue gas needs to cool before $\mathrm{CO}_{2}$ capture or an adsorbent needs to operate efficiently at the temperature of flue gas with high selectivity and high adsorption capacity $[18,19,26]$.
Inherent nature of precursors and activation procedures determine the characteristics of AC. This fact that chemistry of the surface can be easily tailored by incorporation of the desired functional groups is an interesting advantage for AC. According to prior studies on $\mathrm{AC}$, enhanced $\mathrm{CO}_{2}$ adsorption capacity (at ambient and/or elevated temperature) may be achieved by introducing nitrogen functionalities onto AC surface (and so increasing AC surface basicity): Introduction of nitrogen surface groups has been experienced by ammonia treatment [7,10,27-30], impregnation with amine containing compounds $[6,7,26]$ or grafting amine groups [8]. It is well known that amine functional groups have a good affinity toward $\mathrm{CO}_{2}$ through forming complex [9,31-34]. The authors have reviewed the potential methods for grafting amino groups on the surface of AC [35]. These methods include nitration followed by reduction, silylation with aminosilane, amination, grafting diamines and polyamines, grafting halogenated amines and so on. It can be seen from the indicated review paper that grafting halogenated amines is one of the possible methods for anchoring amino groups on AC surface, so it was considered as a part of authors' research.

In the present work, a halogenated amine, 2-chloroethylamine hydrochloric acid (CEA) was grafted on the surface of an oxidized $A C$ and the characteristics of the new adsorbents were studied by different methods. The stage of oxidation was also examined in terms of AC textural and chemical characteristics.

\section{Materials and methods}

\subsection{Materials}

Two types of a microporous palm shell AC produced by Bravo Green Sdn Bhd, Malaysia were the initial materials chosen for modification. As-received ACs were sieved to the size range of 500850 micron $(\mu \mathrm{m})$ and washed with distilled water to remove fines. They then were dried in an oven at $110^{\circ} \mathrm{C}$ overnight and kept in closed bottles for experiment (referred to as A1 and A2). A1 was the main starting material for modification. Moreover, a few experiments were conducted using A2. Fisher Scientific, Malaysia supplied the chemicals including reagent-grade nitric acid, analytical-grade toluene, and CEA.

\subsection{Modification of $A C$}

AC samples were subjected to a two-stage modification. At the first stage, they were oxidized by nitric acid to increases the density of different types of oxygen surface groups and then, at the second stage, two amine-enriched samples were obtained by grafting CEA on the surface of the oxidized samples. Oxidation increases the density of different types of oxygen surface groups. Some types of these groups act as coupling or linking agent for grafting other functionalities. In the case of halogenated amines, $\mathrm{OH}$ bond of Carboxylic group and also phenolic and alcoholic $\mathrm{OH}$ groups created or increased on AC surface may react with that to anchor amine groups on surface [35].

Due to importance of the density of specific oxygen groups for amine grafting, oxidation conditions were investigated to achieve the best oxidized sample for amine anchoring.

The utilized oxidation setup comprised of a round bottom flask put in a heating mantle and connected to a condenser. All oxidation experiments with this setup were performed at boiling temperature of the acid solution.

Table 1 shows conditions of the oxidation experiments. It should be noted that AC sample weight and volume of acid solution were constant through all oxidations.

At the second stage of modification, two amine modified samples CEA1 and CEA2 were prepared by grafting CEA on the 
Table 1

Conditions of the oxidation experiments.

\begin{tabular}{llll}
\hline Sample & Parent & Nitric acid concentration & Time (h) \\
\hline OX4 & A1 & 8N & 2.17 \\
OX5 & A2 & $8 \mathrm{~N}$ & 2.17 \\
OX6 & A1 & 8N & 6 \\
OX7 & A1 & Concentrated & 2 \\
OX8 & A1 & Concentrated & 6 \\
OX9 & A1 & Concentrated & 8 \\
\hline
\end{tabular}

selected oxidized sample (OX4): A known amount of OX4 was put in an Erlenmeyer flask and $200 \mathrm{ml}$ of $1 \mathrm{M} \mathrm{NaOH}$ solution was added and mixed for $24 \mathrm{~h}$. Then it was washed and dried in an oven overnight. The prepared Na-form sample was divided into two equal parts. Both parts were treated with a $1 \mathrm{M}$ solution of CEA, one part using the shaker for $24 \mathrm{~h}$ (CEA1) and the other part in the abovementioned oxidation setup (CEA2).

\subsection{Characterization methods}

$\mathrm{N}_{2}$ adsorption-desorption isotherms were measured by ThermoFinngan Sorptomatic 1990 Series analyzer to determine textural characteristics of the samples. Prior to the measurements, the samples were outgassed at $120^{\circ} \mathrm{C}$ and under vacuum. Adsorption data of the relative pressure $\left(P / P_{0}\right)$ less than 0.3 was used to calculate BET surface area $\left(S_{\mathrm{BET}}\right)$. Total pore volume $\left(V_{t}\right)$ was calculated based on the nitrogen adsorbed volume at the relative pressure of 0.995 .

Temperature-Programmed Desorption (TPD) spectra of the oxidized samples were obtained using a Chemisorb 2720 (Micromeritics) by a method as follows: The samples were exposed to a pure stream of helium with the flow rate of $25 \mathrm{ml} /$ min in the U-shaped tubular reactor of the instrument. After the samples were purged adequately, temperature was increased from ambient up to $1000{ }^{\circ} \mathrm{C}$ under the same helium stream with a heating rate of $10^{\circ} \mathrm{C} / \mathrm{min}$. The difference between thermoconductivities of the carrier gas and the desorbed gases was displayed and recorded by the Thermo Conductivity Detector (TCD) as TCD signal. Proximate analysis was carried out with the aid of TGA to determine the amount of ash, fixed carbon and volatile matter. Ultimate analysis was performed using a 2400 Series II CHNS/O elemental analyzer, Perkin Elmer to evaluate the nitrogen content.

\section{4. $\mathrm{CO}_{2}$ capture measurements}

The amine modified samples were subjected to $\mathrm{CO}_{2}$ capture measurements including isothermal $\mathrm{CO}_{2}$ uptake profile and temperature programmed (TP) $\mathrm{CO}_{2}$ adsorption and cyclic operation with the aid of TGA/SDTA851 Ultramicro Balance, MettlerToledo. For isothermal uptake experiments, the samples were first outgassed from preabsorbed $\mathrm{CO}_{2}$ and water at $120^{\circ} \mathrm{C}$ for $1 \mathrm{~h}$ in $50 \mathrm{ml} / \mathrm{min}$ nitrogen atmosphere and were allowed to become cool to $30{ }^{\circ} \mathrm{C}$, which was the desired temperature for isothermal test. At that moment, the gas was switched to pure $\mathrm{CO}_{2}$ of $50 \mathrm{ml} / \mathrm{min}$ for $1 \mathrm{~h}$ to achieve a complete saturation.

In order to perform cyclic operation tests, a procedure similar to isothermal uptake experiment was repeated three times and considered as three consecutive regenerations, and the samples capacities were compared with the first saturation (isothermal uptake).

For TP $\mathrm{CO}_{2}$ adsorption tests, after the first saturation, the temperature was increased with a ramp rate of $1{ }^{\circ} \mathrm{C} / \mathrm{min}$ from $30^{\circ} \mathrm{C}$ to $120^{\circ} \mathrm{C}$ to obtain $\mathrm{CO}_{2}$ temperature dependence of $\mathrm{CO}_{2}$ adsorption capacity.

\section{Results and discussion}

\subsection{Oxidation}

It is well known that oxidation parameters affect texture and chemistry of the oxidized AC. Therefore, at the first step of this work and to evaluate the influence of oxidation parameters on the AC structure and chemistry in a practical manner, a series of oxidation experiments were conducted.

TPD was employed as a simple technique with reproducible results to compare the amount of surface functional groups created on the surface of AC samples. These surface groups are essentially oxygen-containing ones, because the parent samples have negligible amounts of heteroatoms except for oxygen and it is fully accepted that oxidation principally creates oxygen groups (as will be indicated later in this section using the results of ultimate analysis). Fig. 1 shows TPD spectra of the untreated and treated samples, which have been normalized for the weight of the samples. The area below the curves of spectra can be interpreted as an index presenting the amount of oxygen surface groups. This index has been shown in Table 2 for the oxidized and parent samples.

It is observed from Fig. 1 that in all the oxidized samples, the amount of surface oxygen groups has been increased in comparison with the parent samples A1 and A2. In spite of the difference in the oxidation time of the samples OX4 and OX6, Fig. 1 shows no significant difference in the density of their oxygen groups. This confirms that there is a limitation to the total amount of oxygen groups that can be created on the surface of AC. In other words, active sites on the surface of AC have a limited number. In fact, $2.17 \mathrm{~h}$ that is selected time for OX4 is the time at which the evolution of brownish $\mathrm{NO}_{2}$ gas (which had been started from the beginning of the oxidation) is almost stopped. Evolution of the brownish gas indicates the oxidation reaction [36], so its stopping can be considered as the end of oxidation.

Samples OX7-OX9 have been prepared by concentrated acid. It was found that after $6 \mathrm{~h}, \mathrm{NO}_{2}$ gas was stopped from evolution (OX8). As Fig. 1 indicates there is no significant difference between TPD spectra of OX8 and OX9, although the oxidation time for the latter is $2 \mathrm{~h}$ more than the former. This observation is consistent with the previous statement. The spectrum of OX7 is very similar to that of OX4. Except to the peak located in the temperature range of $250-280^{\circ} \mathrm{C}$, the spectra of OX8 and OX9 is very close to OX4. The mentioned peak that is higher developed in OX8 and OX9 is probably related to carboxylic groups [22,37-39]. However, the samples resulted from concentrated acid had one drawback: the amount of produced fine particles was much more compared to $8 \mathrm{~N}$ acid, especially when the oxidation time increased.

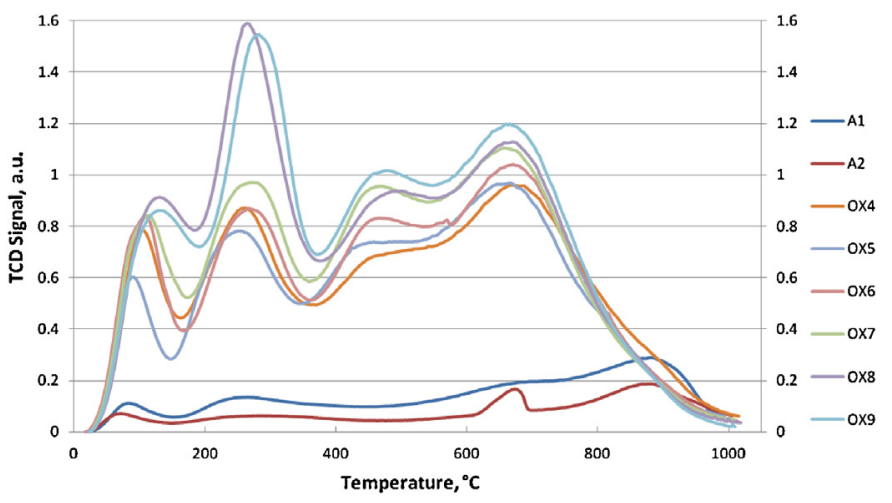

Fig. 1. TPD spectra of virgin and oxidized AC samples. 
Table 2

Textural characteristics and results of proximate and ultimate analysis for oxidized samples.

\begin{tabular}{|c|c|c|c|c|c|c|c|c|c|c|c|}
\hline \multirow[t]{2}{*}{ Sample } & \multicolumn{3}{|c|}{ Proximate analysis (wt\%) ${ }^{\mathrm{a}}$} & \multicolumn{4}{|c|}{ Ultimate analysis (wt\%) } & \multirow[t]{2}{*}{$\mathrm{O} / \mathrm{C}$} & \multirow[t]{2}{*}{$S_{\mathrm{BET}}\left(\mathrm{m}^{2} / \mathrm{g}\right)$} & \multirow[t]{2}{*}{$V_{t}\left(\mathrm{~cm}^{3} / \mathrm{g}\right)$} & \multirow[t]{2}{*}{ Area below TPD } \\
\hline & VM & $\mathrm{FC}$ & Ash & $\mathrm{C}$ & $\mathrm{H}$ & $\mathrm{N}$ & $\mathrm{O}^{\mathrm{b}}$ & & & & \\
\hline A1 & 17.61 & 75.73 & 6.66 & 85.26 & 1.51 & 0.31 & 6.26 & 0.07 & 846.3 & 0.434 & 138.7 \\
\hline A2 & 15.17 & 79.51 & 5.32 & 87.12 & 1.25 & 0.28 & 6.03 & 0.07 & 888.6 & 0.479 & 79.0 \\
\hline OX4 & 35.65 & 61.01 & 3.34 & 69.23 & 2.41 & 0.75 & 24.27 & 0.35 & 420.9 & 0.221 & 574.4 \\
\hline OX5 & 31.47 & 65.21 & 3.32 & 71.06 & 2.4 & 0.61 & 22.61 & 0.32 & 403.9 & 0.198 & 546.1 \\
\hline OX6 & 39.23 & 57.63 & 3.14 & 67.68 & 2.68 & 0.73 & 25.77 & 0.38 & 350 & 0.142 & 601.8 \\
\hline OX7 & 41.04 & 56.39 & 2.57 & 60.23 & 3.91 & 1.23 & 32.06 & 0.53 & 10 & 0.009 & 654.3 \\
\hline OX8 & 43.39 & 54.23 & 2.38 & 57.98 & 3.98 & 2.53 & 33.13 & 0.57 & $<1$ & - & 730.7 \\
\hline OX9 & 43.17 & 54.18 & 2.65 & 57.12 & 4.03 & 1.89 & 34.31 & 0.60 & $<1$ & - & 749.3 \\
\hline
\end{tabular}

a Dry basis.

b Calculated by difference.

A2 was also an AC sample. Its TPD spectrum shows much less amount of oxygen groups in comparison with A1. Nevertheless, OX5 prepared from A2 at the same conditions of OX4, has a TPD curve similar to OX4. This confirms again the limitation of number of active sites accessible for oxidation. It also suggests similarity of the structures of the utilized ACs prepared at different conditions.

As the last point about TPD results, the temperatures of the peaks evolution are paid attention. For all the oxidized samples, the peaks are evolved almost at the same temperatures. From this fact, it can be concluded that the same types of oxygen groups are created on the surface of the samples, despite the significant differences in the conditions of oxidation.

Table 2 presents the textural characteristics of the samples together with the results of proximate and ultimate analysis. The results of proximate analysis present that oxidation leads to a great raise in the volatile content. The volatile content includes the amount of surface functional groups that are decomposed up to $950{ }^{\circ} \mathrm{C}$ [37] and is in total consistency with the area below the curves of TPD spectra and oxygen content determined by ultimate analysis. The ratio of oxygen/carbon, as incorporated into Table 2 indicates the degree of oxidation of the AC surface. According to the table, all these parameters follow the same trends. This fact verifies the validity of the results. Moreover, it can be seen from the same table that the BET surface area $\left(S_{\mathrm{BET}}\right)$ and total pore volume $\left(V_{t}\right)$ of all oxidized samples decrease with oxidation. This matter may be attributed to pore blockage by oxygen groups and/or destructions of pore walls [40-43]. The attention is drawn to samples OX7-OX9. As previously mentioned, a considerable amount of AC granules is converted to powder in samples OX7-OX9 and, as mentioned in Table 2, their surface area is too low. It seems that the oxidation partially or completely destroys these samples.

In the light of above, OX4 is selected for modification with CEA.

\subsection{Grafting amino groups}

Table 3 shows textural and chemical characteristics of the amine-grafted samples. The degree of amine anchoring can be quantified from the rise in the nitrogen content and also volatiles. Ultimate analysis confirms that amine grafted samples have higher contents of nitrogen. Grafting amine groups cause a drastic decrease in surface area and pore volume, as shown in Table 3. The BET surface area of these samples is also less than their oxidized parent, OX4. From these observations, incorporation of nitrogen groups into the structure of $\mathrm{AC}$ is inferred for the modified samples.

Fig. 2 shows the isothermal $\mathrm{CO}_{2}$ uptake profile of the aminegrafted samples expressed as percentage of weight increase versus time at $30^{\circ} \mathrm{C}$, when the samples have been put in pure $\mathrm{CO}_{2}$ atmosphere. It is apparent that $\mathrm{CO}_{2}$ capture capacity of $\mathrm{A} 1$, the parent, is higher than the modified samples at $30^{\circ} \mathrm{C}$. By coupling this fact with data in Table 3, it can be concluded that the higher surface area of A1 is the reason of its higher capture capacity. Although the presence of nitrogen groups is expected to improve affinity toward $\mathrm{CO}_{2}$ and increase contribution of chemisorption, total $\mathrm{CO}_{2}$ capacity is prevailed by physisorption at the low temperatures. However, the role and importance of chemisorption can be realized by other means, as will be explained later in this section. Fig. 2 also shows that the parent A1 is completely saturated with $\mathrm{CO}_{2}$ in a few minutes, whereas in the modified samples, it takes a longer time to achieve equilibrium. In other words, adsorption rate is retarded by amine modification. Moreover, the slopes of the capture curve are alike.

In order to realize the role of chemisorption, $\mathrm{TP} \mathrm{CO}_{2}$ adsorption test was carried out. This test can reveal the effect of temperature on $\mathrm{CO}_{2}$ adsorption capacity of the modified samples, as shown in Fig. 3a. It can be seen from the figure that the capture capacities of untreated and treated samples decline by growing temperature due to prevalence of the physical adsorption mechanism. However, the slope of decrease in A1 is notably more, compared to the modified samples. This finding results in that at elevated temperatures (more than $100{ }^{\circ} \mathrm{C}$ ), CEA1 has a remarkable capacity over A1 and CEA2 has a capacity of near A1, despite of their lower surface area. At $100{ }^{\circ} \mathrm{C}$, capacity of CEA 1 is about $45 \%$ more than that of $\mathrm{A} 1$. This matter suggests that the mechanism of adsorption has been influenced by chemisorption in the amine-containing AC. This fact can be justified by the higher amount of nitrogen functionalities in the form of amino group, as detected by ultimate analysis.

The $\mathrm{CO}_{2}$ capture capacity is resulted from two simultaneous mechanisms of physisorption and chemisorptions; the former depends on porous structure and the latter is affected by amine (or

Table 3

Textural characteristics and results of proximate and ultimate analysis for amine-modified samples.

\begin{tabular}{|c|c|c|c|c|c|c|c|c|c|c|}
\hline \multirow[t]{2}{*}{ Sample name } & \multicolumn{3}{|c|}{ Proximate analysis (wt\%) ${ }^{\mathrm{a}}$} & \multicolumn{4}{|c|}{ Ultimate analysis (wt\%) } & \multirow[t]{2}{*}{$\mathrm{N} / \mathrm{C}$} & \multirow{2}{*}{$\begin{array}{l}S_{\mathrm{BET}} \\
\left(\mathrm{m}^{2} / \mathrm{g}\right)\end{array}$} & \multirow{2}{*}{$\begin{array}{l}V_{t} \\
\left(\mathrm{~cm}^{3} / \mathrm{g}\right)\end{array}$} \\
\hline & VM & FC & Ash & C & $\mathrm{H}$ & $\mathrm{N}$ & $\mathrm{O}^{\mathrm{b}}$ & & & \\
\hline A1 & 17.64 & 75.7 & 6.66 & 85.26 & 1.51 & 0.31 & 6.26 & 0.004 & 846.3 & 0.434 \\
\hline CEA1 & 41.21 & 53.94 & 4.85 & 68.45 & 2.28 & 5.48 & 18.94 & 0.080 & 268.9 & 0.153 \\
\hline CEA2 & 42.87 & 52.14 & 4.99 & 66.26 & 2.24 & 5.19 & 21.32 & 0.078 & 279.8 & 0.162 \\
\hline
\end{tabular}

a Dry basis.

b Calculated by difference. 


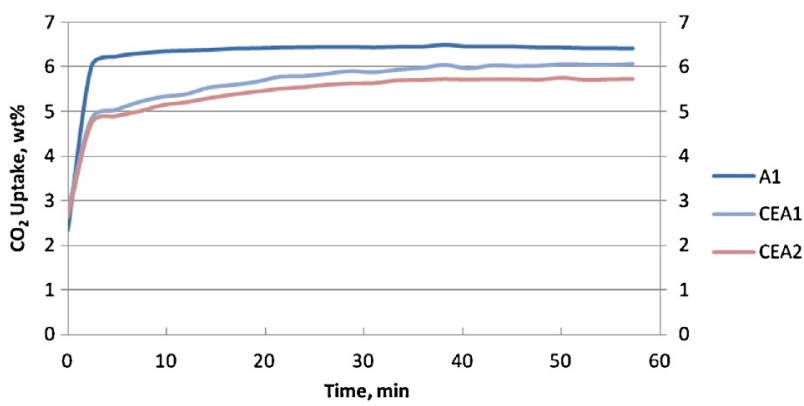

Fig. 2. Isothermal $\mathrm{CO}_{2}$ uptake profile of amine-grafted samples.

nitrogen) content. As the amine modification decrease surface area and increase the amine contents, these two mechanisms are acting inversely. In order to separate the role of chemisorption, $\mathrm{TP} \mathrm{CO}_{2}$ capture curves have been normalized by the BET surface area, as shown in Fig. 3b. The figure shows the effect of amine groups on the capacity of activated carbon in a comprehensible way. It is apparent that the modified samples have a higher capacity than A1 as a result of chemisorption, when they are compared at unit surface area. These observations agree quite well with nitrogen content in Table 3. Compared to A1, CEA1 presents a two- and sixfold increase in capacity at 30 and $115^{\circ} \mathrm{C}$, respectively.

Cyclic operation tests were performed to give an insight into stable performance of the modified samples in practical applications. Fig. 4 shows the capacities of CEA1 and CEA2 for four consecutive adsorption-desorption tests. Cycle number of 0 indicates the first saturation (obtained from isothermal uptake measurements) and other cycle numbers present the following regenerations. According to the figure, the adsorption capacities of the modified samples decrease slightly after first regeneration and are more or less constant after subsequent regenerations. The decrease in capacity after first regeneration can be attributed to the unreleased $\mathrm{CO}_{2}$ resulted from the first saturation. So, higher
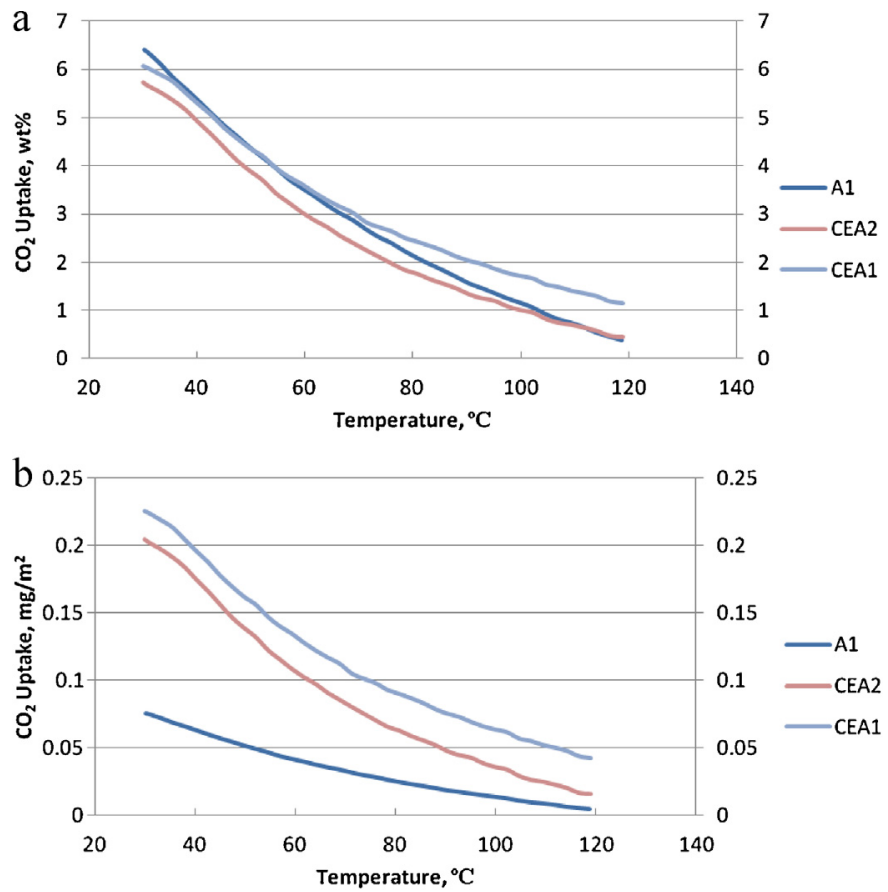

Fig. 3. (a) $\mathrm{TPCO}$ adsorption test. (b) $\mathrm{TPCO}_{2}$ adsorption test, normalized by surface area.

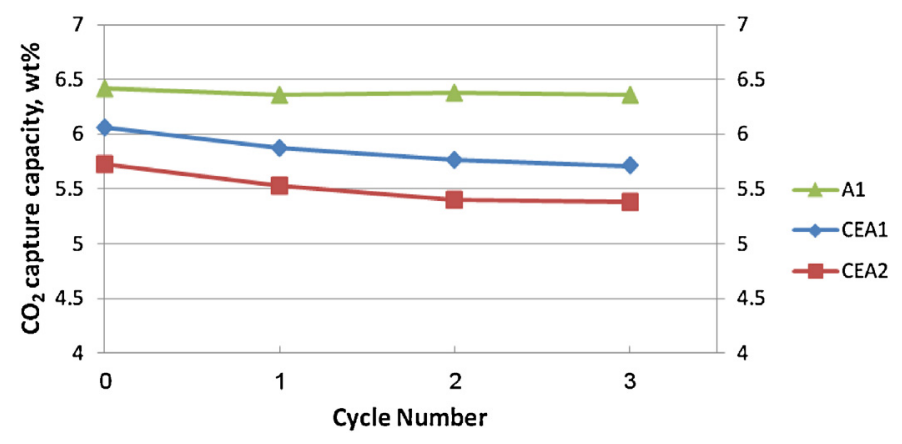

Fig. 4. Cyclic adsorption-desorption tests.

capacities, which are nearer to those obtained from isothermal uptake, may be achieved by higher regeneration temperatures. In this study, initial outgassing temperature $\left(120^{\circ} \mathrm{C}\right)$ was considered as temperature of regenerations. Moreover, no significant accumulation of $\mathrm{CO}_{2}$ is observed during each step of adsorption after first regeneration. This capability of satisfactory regeneration observed from the figure may be considered as a promising sign for stable performance in practical cyclic operations.

\section{Conclusion}

Two modified AC samples were obtained by treatment the virgin samples with two CEA following oxidation. A series of preliminary oxidation was carried out to select a suitable oxidized sample as the starting material for amine modification. The results of amine modification by the selected amine compound are promising. When compared in mass unit, the best modified samples show a $45 \%$ increase in $\mathrm{CO}_{2}$ adsorption capacity at $100{ }^{\circ} \mathrm{C}$. The effect of amine functionalities is expressive when the capacities of the modified samples are compared with untreated one in unit of surface area. A two- to six-fold increase is resulted when comparing the best results with the parent at $30-115{ }^{\circ} \mathrm{C}$.

\section{Acknowledgement}

Financial support by Ministry of Science, Technology and Innovations of science fund "13-02-03-3070" and University of Malaya are gratefully acknowledged. Also, the authors would like to thank the help and support provided by Bright Sparks Unit of University of Malaya for the development of this research work.

\section{References}

[1] Chatti R, Bansiwal AK, Thote JA, Kumar V, Jadhav P, Lokhande SK, et al. Amine loaded zeolites for carbon dioxide capture: amine loading and adsorption studies. Microporous Mesoporous Mater 2009;121:84-9.

[2] Yang HQ Xu ZH, Fan MH, Gupta R, Slimane RB, Bland AE, et al. Progress in carbon dioxide separation and capture: a review. J Environ Sci 2008;20:14-27.

[3] Siriwardane RV, Shen MS, Fisher EP, Poston JA. Adsorption of $\mathrm{CO}_{2}$ on molecular sieves and activated carbon. Energy Fuels 2001;15:279-84.

[4] Maroto-Valer MM, Fauth DJ. Carbon dioxide capture and sequestration preface. Fuel Process Technol 2005;86:1421-2.

[5] Plaza MG, Pevida C, Martín CF, Fermoso J, Pis JJ, Rubiera F. Developing almond shell-derived activated carbons as $\mathrm{CO}_{2}$ adsorbents. Sep Purif Technol 2010;71:102-6.

[6] Plaza MG, Pevida C, Arias B, Casal MD, Martin CF, Fermoso J, et al. Different approaches for the development of low-cost $\mathrm{CO}_{2}$ adsorbents. J Environ Eng 2009;135:426-32.

[7] Maroto-Valer MM, Tang Z, Zhang YZ. $\mathrm{CO}_{2}$ capture by activated and impregnated anthracites. Fuel Process Technol 2005;86:1487-502.

[8] Gray ML, Soong Y, Champagne KJ, Baltrus J, Stevens RW, Toochinda P, et al. $\mathrm{CO}_{2}$ capture by amine-enriched fly ash carbon sorbents. Sep Purif Technol 2004;35:31-6. 
[9] Hiyoshi N, Yogo K, Yashima T. Adsorption of carbon dioxide on modified mesoporous materials in the presence of water vapor. Stud Surf Sci Catal 2004; $154: 2995-3002$

[10] Pevida C, Plaza MG, Arias B, Fermoso J, Rubiera F, Pis JJ. Surface modification of activated carbons for $\mathrm{CO}_{2}$ capture. Appl Surf Sci 2008;254:7165-72.

[11] Huang HY, Yang RT, Chinn D, Munson CL. Amine-grafted MCM-48 and silica xerogel as superior sorbents for acidic gas removal from natural gas. Ind Eng Chem Res 2002;42:2427-33.

[12] Plaza MG, Pevida C, Arenillas A, Rubiera F, Pis JJ. $\mathrm{CO}_{2}$ capture by adsorption with nitrogen enriched carbons. Fuel 2007;86:2204-12.

[13] Wang LF, Ma L, Wang AQ Liu Q Mang T. $\mathrm{CO}_{2}$ adsorption on SBA-15 modified by aminosilane. Chin J Catal 2007;28:805-10.

[14] Contarini S, Barbini M, Del Piero G, Gambarotta E, Mazzamurro G, Riocci M et al. Solid sorbents for the reversible capture of carbon dioxide. In: Greenhouse gas control technologies - 6th international conference. Pergamon: Oxford; 2003. p. 169-74.

[15] Drage TC, Arenillas A, Smith KM, Pevida C, Piippo S, Snape CE. Preparation of carbon dioxide adsorbents from the chemical activation of urea-formaldehyde and melamine-formaldehyde resins. Fuel 2007;86:22-31.

[16] Chaffee AL, Knowles GP, Liang Z, Zhang J, Xiao P, Webley PA. $\mathrm{CO}_{2}$ capture by adsorption: materials and process development. Int J Greenhouse Gas Control 2007; $1: 11-8$.

[17] Franchi RS, Harlick PJE, Sayari A. Applications of pore-expanded mesoporous silica. 2. Development of a high-capacity, water-tolerant adsorbent for $\mathrm{CO}_{2}$. Ind Eng Chem Res 2005;44:8007-13.

[18] Plaza MG, Pevida C, Arias B, Fermoso J, Arenillas A, Rubiera F, et al. Application of thermogravimetric analysis to the evaluation of aminated solid sorbents for $\mathrm{CO}_{2}$ capture. J Therm Anal Calorim 2008;92:601-6.

[19] Arenillas A, Rubiera F, Parra JB, Ania CO, Pis JJ. Surface modification of low cost carbons for their application in the environmental protection. Appl Surf Sci 2005;252:619-24.

[20] Yang RT. Adsorbents: fundamentals and applications. New York: Wiley; 2003.

[21] Aksoylu AE, Madalena M, Freitas A, Pereira MFR, Figueiredo JL. The effects of different activated carbon supports and support modifications on the properties of Pt/AC catalysts. Carbon 2001;39:175-85.

[22] Aguilar C, García R, Soto-Garrido G, Arriagada R. Catalytic wet air oxidation of aqueous ammonia with activated carbon. Appl Catal B 2003;46:229-37.

[23] Hiyoshi N, Yogo K, Yashima T. Reversible adsorption of carbon dioxide on amine-modified Sba-15 from flue gas containing water vapor. Stud Surf Sci Catal 2004;153:417-22.

[24] Biniak S, Szymanski G, Siedlewski J, Swiatkowski A. The characterization of activated carbons with oxygen and nitrogen surface groups. Carbon 1997;35:1799-810.

[25] Wei JW, Shi JJ, Pan H, Zhao W, Ye Q, Shi Y. Adsorption of carbon dioxide on organically functionalized SBA-16. Microporous Mesoporous Mater 2008;116:394-9.

[26] Maroto-Valer MM, Lu Z, Zhang YZ, Tang Z. Sorbents for $\mathrm{CO}_{2}$ capture from high carbon fly ashes. Waste Manage 2008;28:2320-8.
[27] Przepiorski J, Skrodzewicz M, Morawski AW. High temperature ammonia treatment of activated carbon for enhancement of $\mathrm{CO}_{2}$ adsorption. Appl Surf Sci 2004;225:235-42.

[28] Shafeeyan MS, Daud WMAW, Houshmand A, Shamiri A. A review on surface modification of activated carbon for carbon dioxide adsorption. J Anal Appl Pyrolysis 2010;89:143-51.

[29] Shafeeyan MS, Daud WMAW, Houshmand A, Arami-Niya A. Ammonia modification of activated carbon to enhance carbon dioxide adsorption: effect of pre-oxidation. Appl Surf Sci 2011;257:3936-42.

[30] Shafeeyan MS, Daud WMAW, Houshmand A, Arami-Niya A. The application of response surface methodology to optimize the amination of activated carbon for the preparation of carbon dioxide adsorbents. Fuel 2012;94:465-72.

[31] Knowles GP, Graham JV, Delaney SW, Chaffee AL. Aminopropyl-functionalized mesoporous silicas as $\mathrm{CO}_{2}$ adsorbents. Fuel Process Technol 2005;86:1435-48.

[32] Harlick PJE, Sayari A. Amine grafted, pore-expanded MCM-41 for acid gas removal: effect of grafting temperature, water, and amine type on performance. Stud Surf Sci Catal 2005;158:987-94.

[33] Hiyoshi N, Yogo K, Yashima T. Adsorption characteristics of carbon dioxide on organically functionalized SBA-15. Microporous Mesoporous Mater 2005;84:357-65.

[34] Sumida K, Rogow DL, Mason JA, McDonald TM, Bloch ED, Herm ZR, et al. Carbon dioxide capture in metal-organic frameworks. Chem Rev 2012;112: 724-81.

[35] Houshmand A, Daud WMAW, Shafeeyan MS. Exploring potential methods for anchoring amine groups on the surface of activated carbon for $\mathrm{CO}_{2}$ adsorption. Sep Sci Technol 2011;46:1098-112.

[36] Bandosz TJ, Jagiello J, Schwarz JA. Comparison of methods to assess surface acidic groups on activated carbons. Anal Chem 1992;64:891-5.

[37] Figueiredo JL, Pereira MFR, Freitas MMA, Órfão JJM. Modification of the surface chemistry of activated carbons. Carbon 1999;37:1379-89.

[38] Radkevich VZ, Senko TL, Wilson K, Grishenko LM, Zaderko AN, Diyuk VY. The influence of surface functionalization of activated carbon on palladium dispersion and catalytic activity in hydrogen oxidation. Appl Catal A 2008;335:241-51.

[39] Lemus-Yegres LJ, Such-Basanez I, Roman-Martinez MC, Salinas-Martinez de Lecea C. Catalytic properties of a Rh-diamine complex anchored on activated carbon: effect of different surface oxygen groups. Appl Catal A 2007;331:26-33.

[40] Gorgulho HF, Mesquita JP, Goncalves F, Pereira MFR, Figueiredo JL. Characterization of the surface chemistry of carbon materials by potentiometric titrations and temperature-programmed desorption. Carbon 2008;46:1544-55.

[41] El-Sayed Y, Bandosz TJ. Adsorption of valeric acid from aqueous solution onto activated carbons: role of surface basic sites. J Colloid Interface Sci 2004;273:64-72.

[42] Álvarez PM, García-Araya JF, Beltrán FJ, Masa FJ, Medina F. Ozonation of activated carbons: effect on the adsorption of selected phenolic compounds from aqueous solutions. J Colloid Interface Sci 2005;283:503-12.

[43] Strelko JV, Malik DJ. Characterization and metal sorptive properties of oxidized activated carbon. J Colloid Interface Sci 2002;250:213-20. 